line of the ribs) ; no crepitation heard on auscultation over hepatic region. Spleen normal. Appetite poor; flatulence after food; slight constipation; freces of normal colour. Urine: straw-yellow, clear, acid, sp. gr. 1018; no albumen, sugar, biliary colouring matter, or biliary acids. Temperature $98^{\circ}$.

The only prominent symptom, besides the moderate amount of emphysema and bronchitis, being the expectoration of large masses of bile, without the presence of any jaundice, the only admissible diagnosis was "pulmonarybiliary fistula." The primary cause of such fistula was, however, difficult to arrive at. Against an hepatic abscess there was to be set the history of the case, the absence of pain or tenderness over region of liver, the absence of diarrhoea, the very large amount of bile, and the very small amount of pus in the sputum. Against an hydatid cyst was the absence of evacuation of large amount of fluid per sputum in the history of the case, and, further, the normal size and relations of the liver. There remains thus only an idiopathic inflammation of a bile-duct, or an inflammation round such a duct, produced by a gall-stone situated in the liver itself (periangiocholitis).

Idiopathic angiocholitis, however, is extremely rare, and against it was the fact (evidenced by the fæces) that normal bile passed into the duodenum, showing that only a part of the liver could be so affected; whilst, finally, the history of the case gave no clue which could lead one to suppose that gall-stones had formed in the liver and produced periangiocholitis, which in its turn would set up a fistulous communication with the neighbouring organ; yet after death such was found to be the case.

The symptoms remained the same for some days. The quantity of bilious sputum expectorated in twenty-four hours measured from nine to ten ounces. On May 3rd there supervened an attack of vomiting of bilious matter, followed by profuse hæmatemesis. The physical signs remained the same. The urine now contained bile-colouring matter, but no albumen or blood. There was no jaundice.

May 7 th.-Patient continues to vomit; the vomited matter consists sometimes of food, sometimes of bile, and other times of blood. Chest: In right supra-scapular region bronchial expiration, subcrepitant râles, and increased vocal resonance; in right axillary region tympanitic percussion, weak vesicular breathing, and mucous râles.

9th.-Patient much weaker. Physical signs the same; but incessanthiccough, and with every hiccough biliousmatter is brought up. Quantity of sputum, twelve ounces in twentyfour hours. Pulse 70 , very weak; temperature $97 \cdot 8^{\circ}$.

13th. - Condition much worse. Hiccough and sputum continue. Great prostration, but no pain; sensorium free. No food of any sort retained. Pulse 70 ; temperature $97.7^{\circ}$.

The patient now gradually sank, and died on May 15th at 7.50 P.M.

The treatment was purely symptomatic-milk and beeftea, stimulants, ice, hydrocyanic acid, and bismuth.

A utopsy (by Dr. Bradshaw, pathologist to the Infirmary). -The chief changes were found in the stomach, lungs, liver, and peritoneum. The stomach contained dark, grumous masses; it was dilated and softened, and its mucous surface was the seat of numerous ecchymoses. The intestines were found matted together by numerous firm fibrous bands; the peritoneum was thickened in many places. The left lung was the seat of emphysema and congestion; the bronchi slightly dilated, filled with frothy mucus not tinged by bile. The upper surface of liver and lower surface of right lung were bound down to the diaphragm by old adhesions, so that the two organs had to be removed together; it was then found possible to free the diaphragm from these adhesions above and below, till the central tendon was reached; this was converted into a thick, firm, white mass, half an inch in depth, to which lung and liver were inseparably connected. The liver was otherwise normal in size and appearance; its lower surface was traversed by numerous fibrous bands, one of which was tightly stretched across the neck of the gall-bladder, causing obliteration of the cystic duct. The gall-bladder was dilated, filled with clear mucus without a trace of bile, free from gallstones, and completely shut off by the adhesion outside from the cystic duct. On cutting into the liver there were seen the sections of bile-ducts, some perfectly normal and containing clear bile, others dilated, and filled with thick, creamy, yellow fluid; these dilated ducts could be traced to the upper surface of the liver, where they were seen to terminate in a small cavity, situated on the under surface of the altered tendon of the diaphragm, and filled with the same yellow creamy fluid. In this cavity there was found a small branched calculus, consisting of an outer white laye (lime salts), and a darker nucleus (cholesterine and biliary colouring matter); from this cavity a narrow tortuous cana passed into the lung, where it communicated with a bronchus. The liver was normal in structure except near the dilated bile-ducts, where it was the seat of a cellular infiltration, but no true abscesses were discovered. The upper lobe of right lung was hepatised, the lower lobes were in a state of hypostatic congestion. The walls of the fistulous canal consisted of firm fibrous tissue, and the lung-tissue in its neighbourhood was œedematous and stained yellow. The common bile-duct was pervious, and could easily be traced into the duodenum.

Remarks. - The results of the post-mortem examination permit of the following explanation of this most unusual case. The patient's history showed that eight years before the fatal attack he had suffered from severe peritonitis, and after death there were found, as resulting from this, firm adhesions on the under-surface of the liver, and firm bands between the intestines, evidently of very old standing; one of these bands caused the constriction of the neck of the gall-bladder, and in consequence of this no bile conld any longer pass into the gall-bladder, which was found filled with clear mucus (dropsy of the gall-bladder). Owing to the occlusion of this viscus, there must have been stagnation of bile, and this would naturally be greatest at the upper surface of the liver-i.e., furthest away from the large bile. ducts. In the course of time the stagnating and inspissated bile gave rise to the formation of the gall-stone found after death; this calculus, once formed, would act as a fresh irritant, would set up fresh inflammatory changes, adhesions, and suppuration in the neighbourhood, and thus eventually lead to the formation of the fistulous communication.

As already stated, I have not been able to find a similar case on record. Some cases, however, are mentioned by Barth and Besnier (article "Biliare," in the Diction. Ency. clop. des Sciences Médicales), where gall-stones had formed within the liver, and where some of the bile-ducts were found dilated and filled with thick creamy bile, just as in the above case, but in no instance did there exist a fistulous communication with any other organ.

Manchester.

\section{THREE CASES OF LITHOTRITY AT ONE} SITTING.

\section{BY G. BUCKSTON BROWNE.}

IT is now more than a year since Professor Bigelow, of Harvard University, demonstrated before the Clinical Society of London, on an artificial bladder, his method of washing out fragments after the operation of lithotrity; and at the same time he published it as his opinion that the mechanical injury produced by fragments of stone allowed to remain in a bladder after a sitting of lithotrity is greater than that produced by the instrumentation necessary for their prompt removal. He argued, therefore, that the more entirely a bladder can be emptied of its stony contents at the first sitting, the better for the patient. For some time before this the practice of removing small stones at one sitting had been growing into favour, and Sir Henry Thompson had again and again declared that with increased practice and skill he was able to do more at a sitting than he could advise younger and less practised surgeons to attempt. It is doubtful, perhaps, if Professor Bigelow has proved that the bladder and urethra are more tolerant of instrumental interference than they have long been supposed to be, but it seems probable that increased experience will lead the profession to acknowledge the truth of his dictum, that it is the injury done by fragments, and not that done by instruments, which is the chief source of the misfortunes which sometimes follow a crushing. Professor Bigelow, in common with all surgeons experienced in urinary surgery, would not desire anyone to he tempted by his observations to lose that wholesome respect for the extreme sensibility of the 
male urethra which is so becoming to the surgeon contemplating any interference, however slight, with that canal.

Since Professor Bigelow's demonstration, many cases of lithotrity performed upon his principle, although I believe not with his instruments, have been put on record. Sir Henry Thompson has published thirteen cases, Mr. Cadge five, and other surgeons have published single ones. As a further contribution I beg to offer a sketch of three cases which I have lately operated upon while in charge of Sir Henry Thompson's practice during his recent holiday. In all three instances his lithotrites were used, and the bladder washed out through a No. 16 (English) evacuating silver tube, with his india-rubber aspirator described in THE LANCET for Feb. 1st, 1879. I have followed Sir Henry's advice, and have avoided irritating the bladder by a prolonged search for the last fragment. In each case within a week of the operation the bladder was carefully explored to make sure no particle of stone remained ; in the first case only a small piece was found and removed. On each occasion ether was administered by $\mathrm{Mr}$. Clover.

CASE 1.-R. H-, aged sixty-nine, was seen with Dr. Dobell on Sept. 18th. For eight years he had had pain and trouble in micturition. Three months before he had learned to pass a catheter night and morning. He complained of a "queer sensation along the penis" after passing a catheter. He stated that he was worse if he moved about, and that the pain along his penis was constant. He was sounded, and stone discovered.

On Sept. 20th lithotrity was performed, and the stone proved to be multiple uric acid. One hundred and twenty grains were removed in less than fifteen minutes. On Sept. 24th he was examined under ether; a small fragment detected and removed. Two days later he was free from pain. He conld hold his water two hours and a half, and said he felt much relieved. On Oct. 3rd he went home. Three weeks after he complained of a little pain; a lithotrite was introduced, and forty grains of phosphatic matter removed. On Nov. 7th his son wrote-"Water much im. proved ; he is easy from pain."

CASE 2. C. W-, aged sixty-three. I saw the case with Dr. Palfrey. $\mathrm{He}$ had long passed a catheter twice daily. He now made water every hour, day and night. Had much pain at the end of micturition. Moving about gave much suffering. He had not passed his catheter for a week on account of the pain. He was sounded, and a considerable-sized phosphatic stone discovered.

On Oet. 8th the stone was crushed, and 160 grains removed in twelve minutes. Next day he held his urine two hours, but had some soreness. The urine was free from deposit. The temperature was normal.

On Oct. 15th he was put under ether, examined fully, and nothing found. He rapidly improved, and on the night of Oct. 19th only rose once to pass water. In the daytime held his water two to four hours. No pain at all in micturition or on moving about. On the $20 \mathrm{th}$ went home, and has since remained perfectly well.

CASE 3.-C. T—, aged sixty-six, seen with Dr. R. T. Smith, of Haverstock-hill, on Oct. 7th. Sir Henry Thompson had, on Aug. 14th, found a rough, hard, mediumsized stone. The patient's sufferings had increased, and at length became almost unbearable. Micturition was frequent, and the urine was loaded with mucus.

On Oct. 10th I performed lithotrity, and removed in ten minutes 154 grains of mixed urates and phosphates. Improvement was immediate, so that next day he was able to hold his water four hours.

On Oct. 12th there was some irritability of the bladder, and the urine contained mucus. A catheter was passed, and the bladder washed out. Two hours after he had a rigor, followed by no ill effects. He rapidly recovered, and on Oct. 24th a careful sounding failed to detect anything. The patient has since continued perfectly well; he has no pain, and his urine is quite free from deposit.

Testimonial to Dr. Andrews, of Belfast.-A committee has been appointed to receive subscriptions for the purpose of commemorating the retirement of this gentleman from the Vice-Presidency of the Queen's College, Belfast, by a bust or portrait to be placed in the College, and a prize or scholarship to be founded in the same institution in connexion with chemical science. Dr. Andrews is a chemist of world-wide fame; and four years since acted as President of the British Association at the meeting of that body in Belfast.

\section{ON TRANSITORY AN ASTHESIA AFTER UNI- LATERAL CONVULSIONS, WITH OBSERVA- TION ON PERCUSSION OF THE SKULL.}

BY ALEXANDER ROBERTSON, M.D., F.F.P.S.G., PHYSICIAN TO THE TOWN'S HOSPITAT, AND ASYLUM, GLASGOW LECTURER ON MENTAL DISEASES IN THE GLASGO
IYFIRMARY SCHOOL OF MEDICINE, ETC.

IT is well known that an ephemeral loss of power in the arm and leg of one side may immediately follow an attack of convulsions which has been confined to, or, at all cvents, has chiefly affected, that side. It does not, however, appear to have attracted attention that a brief impairment or loss of sensibility in the same members may be, and probably generally is, associated with this form of palsy. The following case, lately in this hospital, illustrates their coexistence.

J. $\mathrm{N}-$ age thirty-nine, engineer, of average intelligence, has been epileptic for upwards of seven years, and the fits have occurred about once in four or five weeks; the longest interval between them, previous to the last seizure, about five months since, having been six weeks. They have always begun on the right side, generally in the hand, but sometimes in the foot. Though beginning in this way, they have often ultimately involved the whole body, and such seizures are accompanied by unconsciousness; but some are confined to the right arm or leg, with retention of consciousness (Jacksonian epilepsy). There is always an interval of a minute or two before the convulsions become general. Patient feels acute pain in the arm and leg when they are convulsed.

I happened to enter the ward at the close of the convulsive stage of the last fit, which was one of the more severe kind. His mind had become quite clear within five minutes after my entry. I then proceeded to test the motor and sensory power in the right extremities, which, as in previous seizures, had been much more convulsed than those on the left side. The following were the results:-1. Motor power: Ten minutes after the fit ceased, no pressure was felt by me when he tried to squeeze my fingers with his right hand, though he grasped them moderately firmly with the left one. At twenty minutes (tested by Duchenne's dynamometer) pressure exerted by right hand $2 \mathrm{lb}$, by left one $35 \mathrm{lb}$.; at fifty-five minutes, right hand $26 \mathrm{lb}$., left $37 \mathrm{lb}$. ; at two hours, right hand $54 \mathrm{lb}$., left $51 \mathrm{lb}$. Patient is right-handed. At twenty minutes he could scarcely raise right leg from the bed, but afterwards power was recovered pari passu with the arm. 2. Sensation : At ten minutes after the fit he scarcely felt sharp pinching in the right hand or foot, though sensibility was not appreciably diminished in the left ones; at twenty minutes (tested by resthesiometer) the two points of the instrument were felt as one at eight inches, both on the front and back of the right hand and wrist, whereas they were felt as two at an inch and a quarter on the palm, and at three inches on the back of the left hand; at an hour both points were recognised on the front of the middle finger of the right hand at one inch, and on the corresponding finger of the left hand at three-quarters of an inch; sensation being thus all but restored in the affected hand.

In this case the character and course of the convulsive action point to the motor region of the surface of the brain on the left side as the probable seat of lesion. And this probability is strongly corroborated by the fact that on tapping the head somewhat firmly, with the finger used as a pleximeter, no pain was felt anywhere except on the left side in an area about two inches in diameter, the centre of which is about two and a half inches above the highest part of the left ear. ${ }^{1}$ The patient was not aware of any disagreeable sensation in that part of the head till the skull was percussed. This observation was made four days after the $t i t$, and, acting on this distinct indication of local disease, a succession of cantharides blisters was ordered to the region of pain; and at the present time nine have been applied. Along with the first of these local applications, a change was made in the constitutional treatmient. Previonsly he had been getting iodide of potassium in eight-grain doses, thrice daily, for weeks together, alternating with fifteen-grain doses of the bromide of potassium

1 The patient was shown, and this point demonstrated, at a meeting of the Glasgow Pathological and Clinical Society. 